\title{
Promoting Urban Water Bodies as a Potential Strategy to Improve Urban Thermal Environment
}

\author{
Nedyomukti Imam Syafii ${ }^{*}$ \\ Received: January 20, 2021 | Revised: May 25, 2021 | Accepted: June 08, 2021 \\ doi: 10.5937/gp25-30431
}

\begin{abstract}
Cities are found warmer than in nearby surrounding rural areas due to change in surface properties and lack of evaporation, indicated as urban heat island (UHI). On the other hand, bodies of water have been known to generate a positive impact on the urban microclimate by maintaining a cooler thermal environment. Although researchers have been conducted many experiments and measurements to illustrate its potential benefits, most of them are studied in terms of its capacity to ameliorate the air temperature. In this paper, the benefits of urban water bodies are evaluated regarding their radiation properties. With the main objectives to find a novel approach to take advantage of urban water bodies' abilities to improve the urban thermal environment, a series of field measurements have been conducted inside an urban scale model. Generally, the measured long-wave and short-wave radiation within the urban canyon shows that bodies of water tend to absorb and store more heat, which in turn generate lower surface temperature as compared to those flat concrete surface.
\end{abstract}

Keywords: urban microclimate; water bodies; field measurement; outdoor scale model; radiation

\section{Introduction}

Cities tend to experience a warmer thermal environment than their surrounding areas due to their urban surface properties, creating well-known Urban Heat Island phenomena (UHI). Among many factors contributing to its formation, UHI is mainly caused by a large variety of land use, such as urban geometry and urban fabric. These factors create distinctive thermal characteristics that differ from those found in rural areas (Landsberg, 1981; Paramitha \& Fukuda, 2014; Paramita \& Matzarakis, 2019; Akbari \& Kolokotsa, 2016). The lack of evapotranspiration and dominance of hard surface affect the storage and transfer of radiative heat that alters the radiation balance. Which in turn, increased absorption of radiation and sensible heat released by urban structures result in a warmer air temperature in cities (Harman \& Belcher, 2006). UHI is also known to contribute to various urban problems such as high energy consumption, thermal discomfort, deterioration of health and wellbeing (Chao et al., 2020; Varquez \& Kanda, 2018; Tzavali et al., 2015). While these artificial surfaces tend to negatively affect the microclimate (i.e., surface temperature and air temperature), urban greens and urban blues have favourable impacts by ameliorating the UHI effect through creating cooler spots and comfortable spaces (Gunawardena et al., 2017; Amani-Beni et al., 2018; Völker et al., 2013; Li \& Yu., 2013).

Especially of bodies of water located in towns and cities, many researchers have found that its ability to ameliorate the air temperature is prominent, especially during the day (Jacobs et al., 2020; Syafii et al., 2017; Jin et al., 2017; Gross., 2017). Correspondingly, its surface temperature is also lower than those found in the surrounding urban fabric, primarily due to evaporation cooling (Lin et al., 2020). In particular, evaporative cooling from bodies of water is considered a com-

\footnotetext{
A Universitas Gadjah Mada, Bulaksumur, Yogyakarta, Indonesia 55281

* Corresponding author: Nedyomukti Imam Syafii, e-mail: nedyomukti@ugm.ac.id; tel: +6282229990620
} 
mon form of passive cooling. The thermal environment around and above the body of water is somewhat distinctive from that of the concrete ground due to changes in the way the water cools and heats. Bodies of water are considered great absorbers, but they also show little thermal response due to their distinctive characteristics (Oke, 1987; Pearlmutter et al., 2009). Body of water allows the transmission of radiation wave to enough depths while the existence of convection permits the heat gain to diffuse through large volume. Body of water also has unlimited moisture for evaporation, which provides an efficient latent heat sink. Lastly, water bodies have a relatively exceptional large thermal capacity as compared to the concrete surface (Gunawardena, 2017). Regarding surface energy balance, where bodies of water within the urbanized area are usually found to swallow, the radiation exchange is expected to dominate the energy budget during low wind speed conditions (Van Hove et al., 2015). These features are likely to make the surface temperature of bodies of water colder than those found on the ground, resulting in a cooler air temperature above the bodies of water. These reductions of temperature are most likely to illustrate the act of bodies of water as a thermal buffer due to its relatively larger thermal inertia (Ampatzidis \& Kershaw, 2020). Due to cooling by evaporation, the process raises the latent heat portion of the surface energy balance and impacts the other energy portion (i.e. sensible heat and stored energy). These continuous processes increase the latent heat, reduce the stored energy's magnitude, and eventually lower its immediate surrounding air temperature.

Thus, the present study aims to evaluate these cooling benefits in regards to their radiation properties. A series of field measurements were conducted inside an outdoor scale model, namely COSMO (Comprehensive Outdoor Scale Model), to make an apparent extent of the bodies of water cooling effect. The COSMO generic form provides an effective evaluation tool for microclimate study within a relatively uniform area. Compared with more complex real-world conditions, the scale model field measurements yields results that are easier to interpret and suitable for assessing urban microclimate. (Kanda, 2006; Kanda et al., 2007; Kawai \& Kanda, 2010a; Kawai \& Kanda, 2010b; Park et al., 2012).

\section{Study area and methodology}

With the main objectives of finding a novel approach to take advantage of urban water bodies' abilities to improve the urban thermal environment, a series of radiation exchange measurements was performed within the outdoor scale model canyon. The field measurement was conducted during the summer season of 2016 alongside the other thermal assessment and evaluation (Syafii et al., 2017). COSMO (Figure 1) is a 1:5 scaled-down simplified residential district in Japan that consists of a cubical array of 512 concrete cubes situated in Saitama Prefecture, Japan (Kanda,
2006; Kanda et al., 2007). The concrete cubes are 1.5 $\mathrm{m} \times 1.5 \mathrm{~m} \times 1.5 \mathrm{~m}$ each, painted dark grey and hollow. They are arranged in a lattice-type square with intervals of $1.5 \mathrm{~m}$, creating urban canyon-like formations. The outdoor scale model's ability to recreate thermal patterns similar to actual urban conditions shows a promising way to study under actual climate conditions comprehensively.

The three-dimensional (3D) short-wave and longwave radiation within the outdoor scale model canyon were measured with a net radiometer to achieve
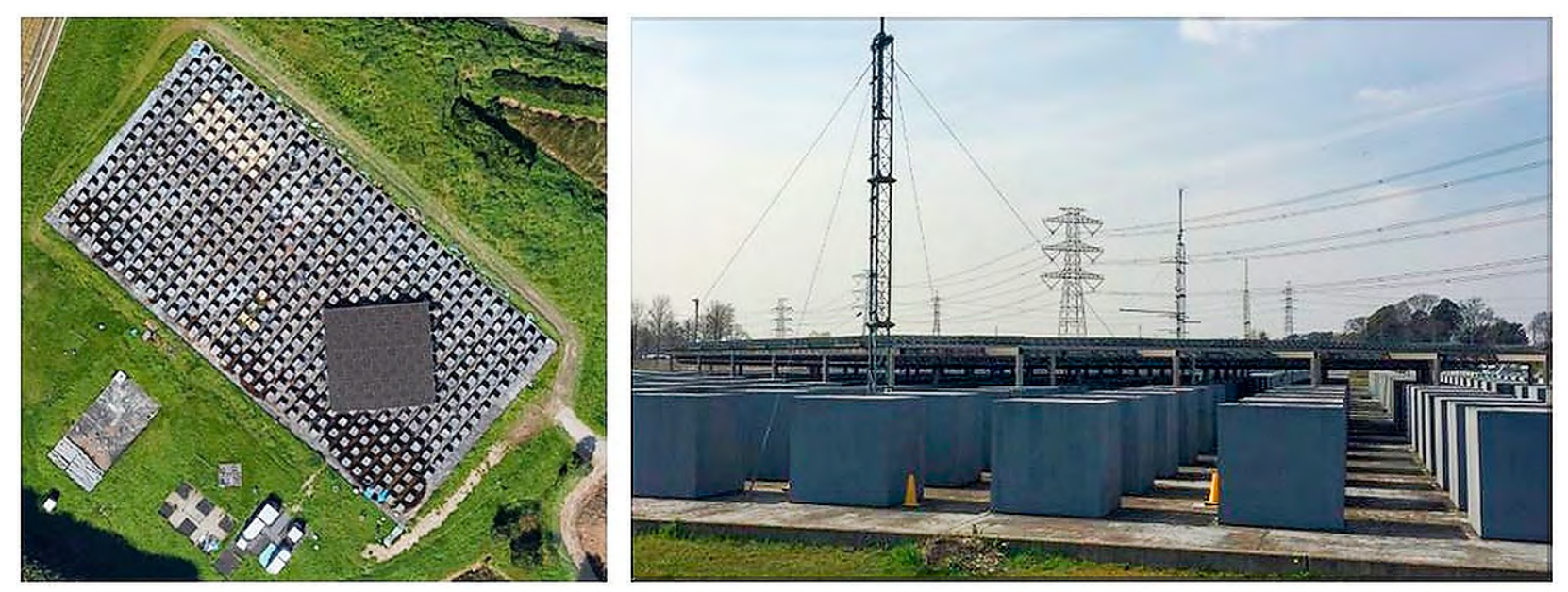

Figure 1. COSMO (Comprehensive Outdoor Scale Model), Saitama, Japan Source: https://www.google.com/earth/ (left image) 

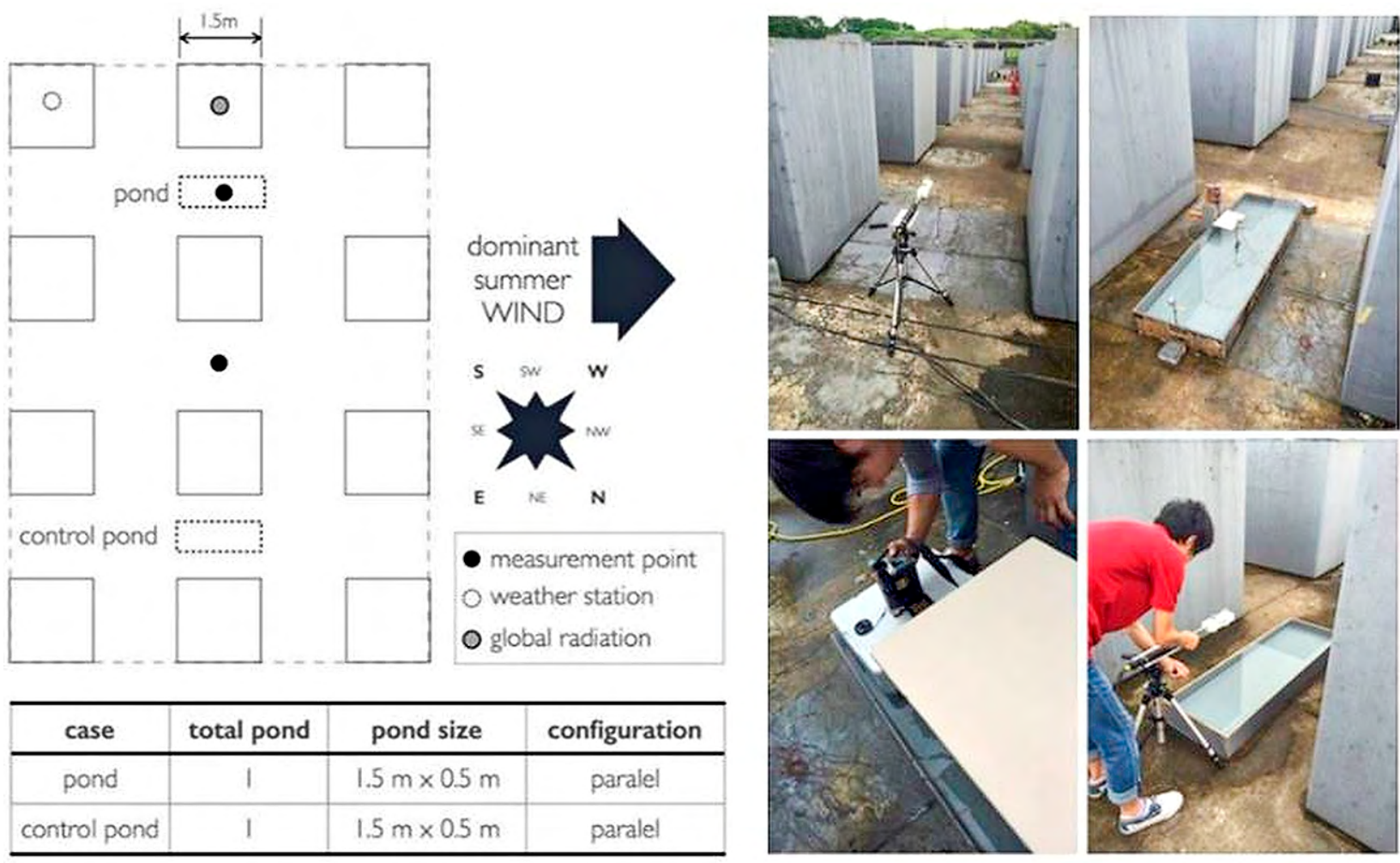

Figure 2. Experimental studies arrangement on the radiation exchange

the study's objectives, utilizing a simplified integral radiation measurement process. The radiation properties of a canyon with bodies of water is compared to a non-water condition. The body of water is in the shape of a $1.5 \mathrm{~m} \times 0.5 \mathrm{~m}$ water pond. Figure 2 illustrates the experimental setting for the radiation exchange measurements. The Net Radiometer (Eko MR-60) monitored four different radiation components (incoming and outgoing radiation fluxes, both long-wave and short-wave) and placed on a tripod (40 cm above the ground). The data was collected once every $10 \mathrm{sec}$ for two days on a typical hot summer day.
Concurrently, the experimental study also monitors both (water and concrete) surface temperature alongside the integral calculation of radiation. A thermal camera unit (infRec R500 pro) was used to capture both surface temperature. During the monitoring process, the thermal camera unit was shielded with a custom build polyurethane box to restrict the effect of other surface-related radiation (Figure 3). These supplementary measurements were utilized to determine the correlation between the integral radiation measurement result and the difference in the surface temperature value, which might illustrate the indirect cooling effect of bodies of water.
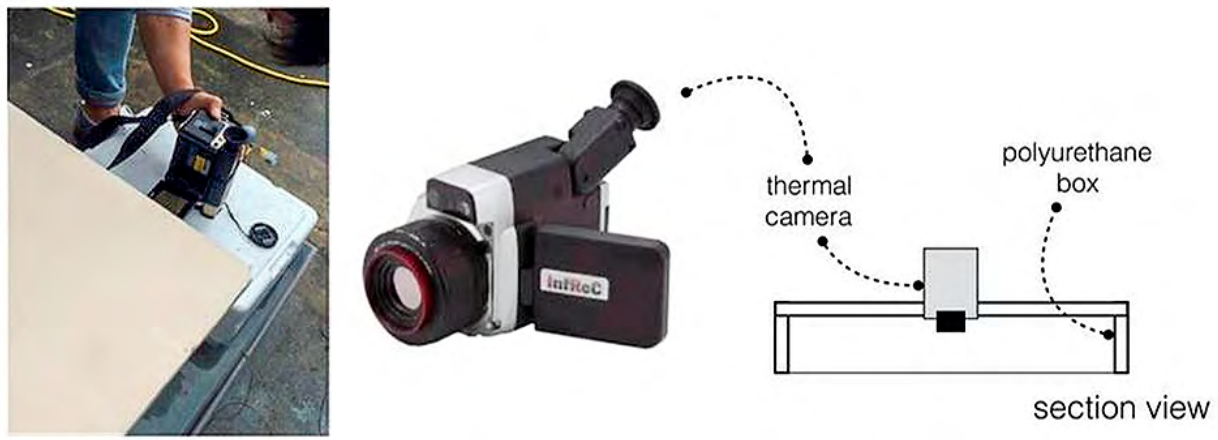

Figure 3. Surface temperature monitoring equipment and setting 


\section{Results and discussion}

The experimental study objective is to better understand the general effect of bodies of water toward urban microclimate in regards to its radiation properties. The following discussion reports the monitored radiation exchange and surface temperature above two different surfaces modification, namely water pond and concrete ground, during the summer season in Japan. The hourly average of the measured incident radiation (long-wave, $L w$, and short-wave, Sw, radiation) above the concrete ground and the pond is shown in Figure 4, respectively. The "down" represents the direction where the incoming radiation comes from the concrete floor or water surface, whereas "up" means the incoming radiation from the sky. On the other hand, the incoming radiation from the short axis and the long axis, relative to the COSMO canyon will be denoted as SW-NE (South West - North East direction) and SE - NW (South East - North West direction) as shown on Figure 1. Additionally, the radiation properties are following the spatial variation of radiation balance on high latitudes of Japan, where they might be experiencing deficit net radiation (Dingman, 2014). Regardless, this paper focuses more on the distinctive profile of radiation exchange between two different surface conditions, water and concrete, inside an urban canyon. The result hopefully shows the potential benefits of having bodies of water in cities. (a)

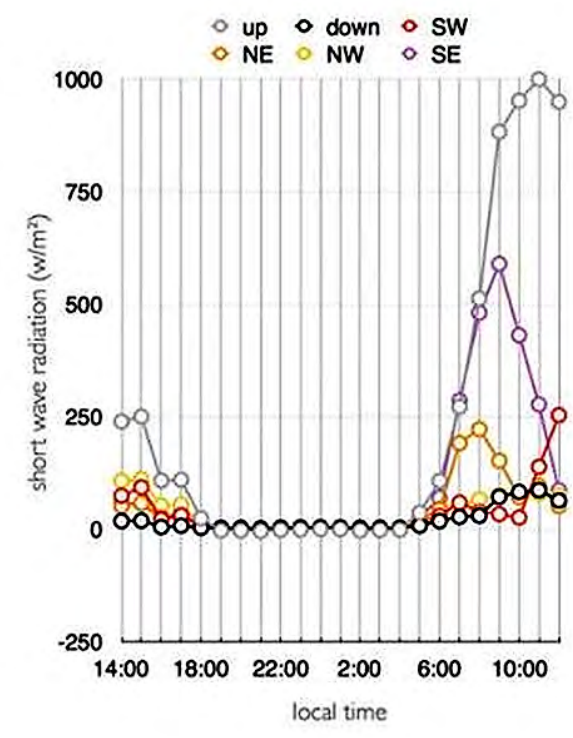

(b)

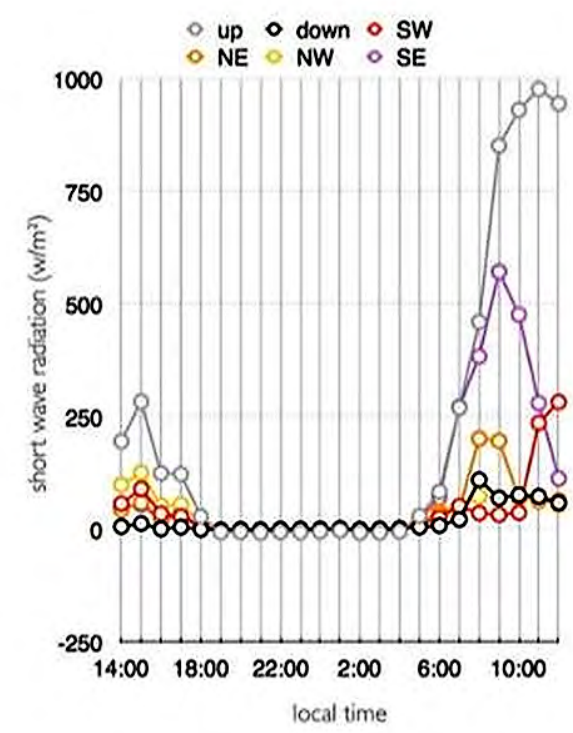

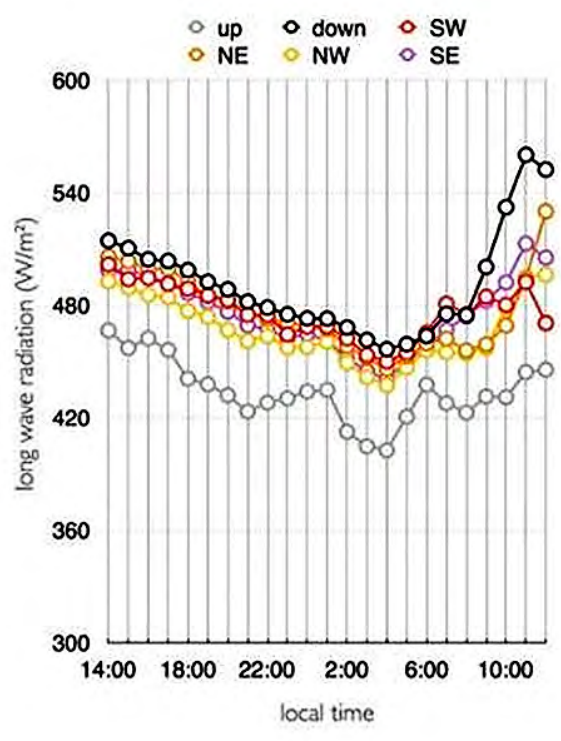

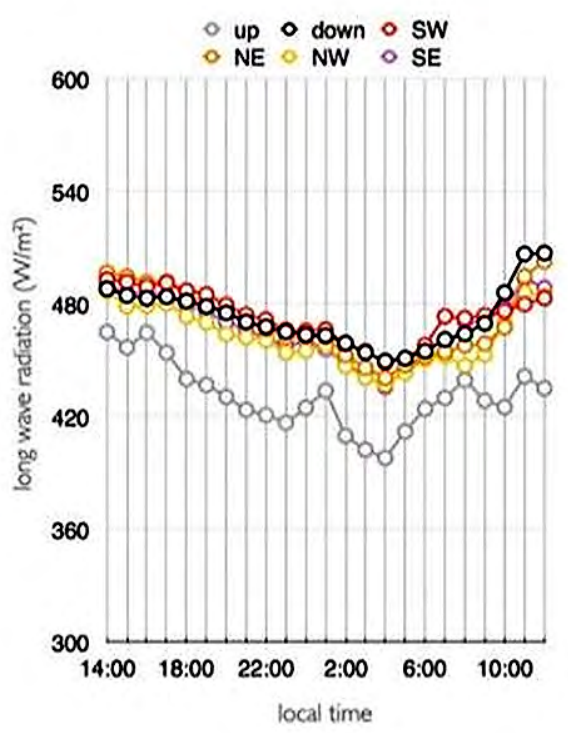

Figure 4. The above-the-concrete-surface (a) and above-the-water-pond (b) measured Short-wave - Sw and Long-wave - Lw radiation (hourly averaged) 
For the most part, similar diurnal trends exist on both radiation profile. The incoming short-wave radiation ( $S w)$ from the up direction (the sky) and the long-axis of COSMO was prominent during the day. The $S w$, which is mainly composed of the direct component of the incoming radiation, seems to be associated with the degree of openness relative to the sky. These incoming radiations show higher value than those incoming radiation from the immediate wall or the short-axis (i.e., SW and NE direction). On the other hand, the incoming long-wave radiation $(L w)$ from below (i.e., the ground surface) was found to be stronger than the other portion of recorded $L w$ radiation. These findings suggest that the ground surface tends to release more heat as a consequence to have more exposure relative to the sky. The $L w$, which mainly shows the conduction and convection portion of the re-radiation from the stored heat, tends to release exceptional heat if the surface or the urban element absorbed more heat. These tendencies are comparable to the $S w$ profile, where the monitored radiation coming from the long axis has shown stronger intensities than the radiation coming from the COS$\mathrm{MO}$ wall. These patterns further emphasized that the radiation exchange within the urban canyon was primarily generated by the sky and the ground part rather than by the vertical canyon surfaces. That further highlights the vital role of ground surface alteration in towns and cities for a better thermal environment. These thermal characteristics are also observed with those obtained from the numerical model, where the local sky view primarily influences the outgoing $L w$ (Harman \& Belcher, 2006).

While both surfaces have similar daily patterns, the intensity of the measured radiation is of different significance. Figure 5 illustrates the difference between the recorded radiation component from above the concrete surface relative to the pond to further understand the phenomena. The radiation portion from the sky was omitted from the analysis, assuming that the values are the same. In the graph, the positive value implies that the radiation component coming from the concrete surface is relatively stronger, and the negative value illustrates the opposite. Overall, the chart shows a fluctuating short wave differential $(\Delta \mathrm{Sw})$ value yet more constant in the long-wave differential $(\Delta \mathrm{Lw})$ value. The $\Delta \mathrm{Sw}$ profile indicates that under all conditions, with or without a water pond, the Sw radiation portion tends to have the same state during the night when there was no sunshine. In the daytime, it was relatively fluctuating, with most of the Sw coming from the long canyon axis when there was no water pond, especially during the morning time. However, when the pond was present, the $S w$ was primarily recorded coming from the water at the end of the daytime period. The findings suggest that the pond tends to reflect the $S w$ radiation component, especially when the angle of the incident light was relatively high, creating fluctuating radiation properties.

Furthermore, the calculated $\Delta \mathrm{Lw}$ profile suggests a stronger radiation intensity above the concrete surface during the day, especially the radiant portion coming from below. The concrete ground appears to release greater radiation in comparison to those coming from the pond. Also, the rise in the calculated $\Delta \mathrm{Lw}$ value tends to be associated with direct radiation from the sun. The recorded high value of long-wave radiation difference in the daytime period might indicate the capacity of the pond to store and retain notable heat. In contrast, the concrete surface tends to release the radiation back to the atmosphere immediately. Due to water availability, $L w$ above the water ponds also
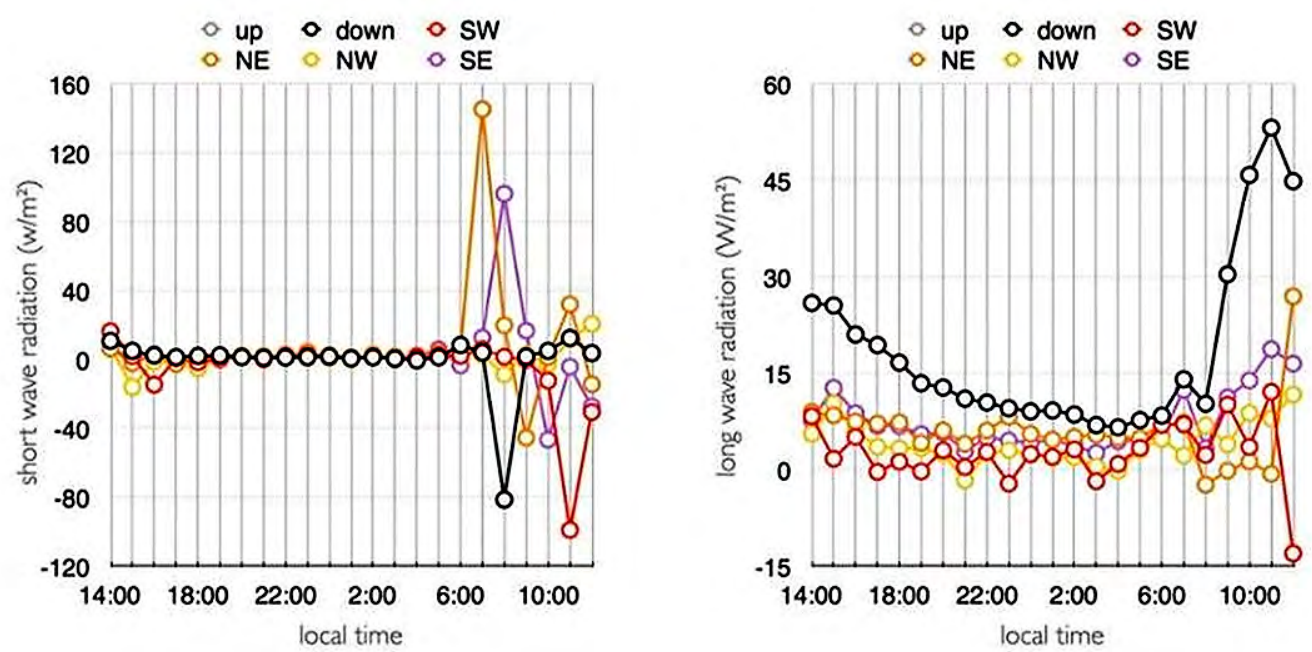

Figure 5. The difference of measured short-wave $(\Delta \mathrm{Sw})$ and long-wave $(\Delta \mathrm{Lw})$ radiation above the concrete ground relative to the pond 
comes in the form of latent heat flux from the evaporation process, which considers beneficial to the urban thermal environment (de la Flor \& Domínguez, 2004; Robitu et al., 2006; Dingman, 2014).

Meanwhile, as the heat begins to re-radiate from the surfaces in the nighttime period, the monitored $\Delta \mathrm{Lw}$ indicates a declining trend towards sunrise. Even though the concrete surface has a relatively high radiation value, the pattern suggests that the heat intensity generated by the pond appears comparatively stronger, which compensates for the high Lw radiation recorded coming from the ground concrete surfaces. There is a possible warming effect due to the water pond's presence, as found by (Steeneveld et al., 2014; Theeuwes et al., 2013). Still, the radiation profile shows that the water pond seems to perform better than the concrete surface regarding the undesirable excess of heat. These tendencies lead to lower re-radiation and trapping of heat inside the urban canyon.

This radiation profile, which was produced from different surface conditions, was naturally converted into different surface temperatures (Ts). Lower heat release from the water surface would result in cooler surface temperatures (Robitu et al., 2006). As seen on the monitored Ts (Figure 6), the recorded water Ts can be up to $14{ }^{\circ} \mathrm{C}$ cooler than the concrete surface in the daytime period. Under this ideal condition, the lower $T s$ could also mean reducing the availability of latent heat flux, which might reduce the cooling effect (Gunawardena, 2017). However, the diminishing pattern of $T s$ during the nighttime period tends to match

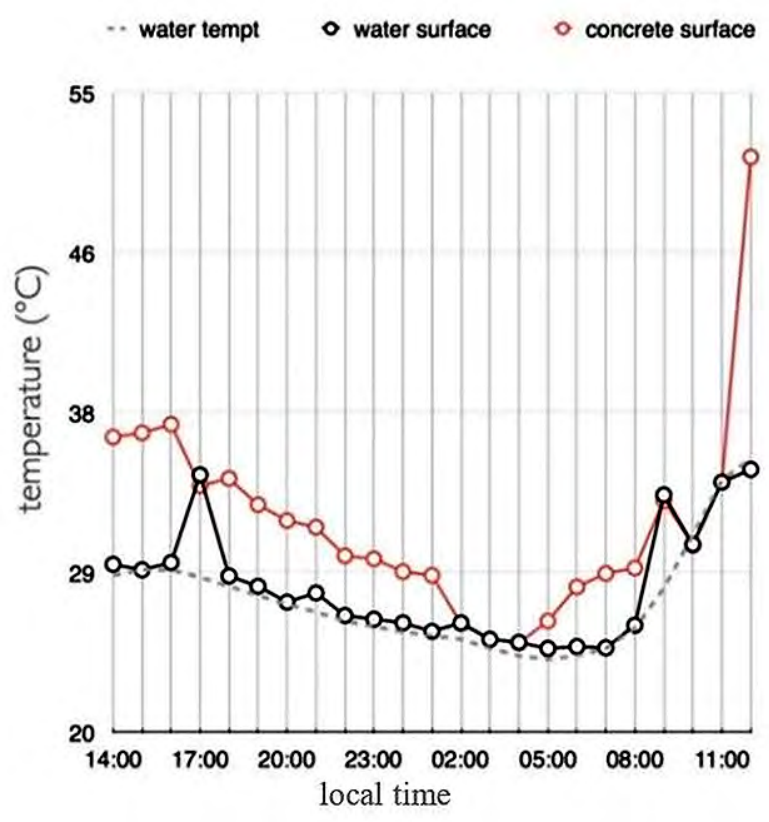

Figure 6. The comparison of measured surface temperature $(T s)$ of water and concrete (hourly average) taken from the thermal camera

the diminishing trend of $L w$, which most likely indicates that the most crucial element in the fluctuation of surface temperature within an urban canyon is the long-wave radiation component. These findings further suggest that the ability of the pond to regulate the radiation exchange could ameliorate the surface temperature, which in turn benefits its surrounding microclimate by creating a cooler air temperature.

\section{Conclusion}

The mitigation capacity of bodies of water shows potential benefits in improving the thermal environment in towns and cities. Generally, water not only aesthetically pleasing but could increase the thermal quality of urban microclimate. Primarily through evaporation, bodies of water ameliorate the warm urban air temperature. The evaporation process alters the radiation exchange and surface energy balance by cools its surface temperature, thus creating a beneficial thermal environment.

With a focus on the quantitative analysis, the monitored long-wave $(L w)$ and short-wave $(S w)$ radiation within the urban canyon illustrate a phenomenon where water bodies tend to absorb and store more heat than flat concrete surfaces. The ex- perimental study result confirms the degree of the pond impact on the radiation properties within the urban canyon, creating notable cooler surface temperatures. These findings provide a future possibility of altering urban water bodies' ability to modify their radiation properties by changing their heat capacity (i.e., maintaining lower water temperature, increasing water mass, etc.). These physical parameters, which can be controlled by preserving positive responsiveness to heat, should be taken into consideration when bodies of waters are built to mitigate the severe impact of UHI. Such results also indicate that bodies of water should be integrated into future planning and design in towns and cities to enhance the quality of the thermal environment. 


\section{Acknowledgement}

This paper was supported by the Ministry of Research and Technology/National Research and Innovation Agency of Republic Indonesia. Simulasi Kinerja Bangunan dalam Proses Studio Desain Grant numbers 458/UN40.D/ PT/2020 under LPPM Universitas Pendidikan Indonesia. The author would also like to extend his gratitude to assoc. Prof. Masayuki Ichinose (Tokyo Metropolitan University) for his endless support and valuable advice.

\section{References}

Akbari, H., \& Kolokotsa, D. (2016). Three decades of urban heat islands and mitigation technologies research. Energy and Buildings, 133, 834-842. https:// doi.org/10.1016/j.enbuild.2016.09.067

Amani-Beni, M., Zhang, B., Xie, G., \& Xu, J. (2018). Impact of urban park's tree, grass and waterbody on microclimate in hot summer days: A case study of Olympic Park in Beijing, China. Urban Forestry \& Urban Greening, 32, 1-6. https://doi.org/10.1016/j. ufug.2018.03.016

Ampatzidis, P., \& Kershaw, T. (2020). A review of the impact of blue space on the urban microclimate, Science of The Total Environment, 730, 2020, 139068. https://doi.org/10.1016/j.scitotenv.2020.139068

Chao, Z., Wang, L., Che, M., \& Hou, S. (2020). Effects of Different Urbanization Levels on Land Surface Temperature Change: Taking Tokyo and Shanghai for Example. Remote Sensing, 12, 2022. https://doi. org $/ 10.3390 /$ rs 12122022

Couts, A. M., Tapper, N. J., Beringer, J., Loughnan, M. \& Demuzere, M. (2013). Watering our cities: The capacity for Water Sensitive Urban Design to support urban cooling and improve human thermal comfort in the Australian context. Progress in Physical Geography: Earth and Environment, 37(1), 2-28. https://doi.org/10.1177/0309133312461032

de la Flor F. S., \& Domínguez, S. A. (2004). Modelling microclimate in urban environments and assessing its influence on the performance of surrounding buildings, Energy and Buildings, 36 (5), 403-413. https://doi.org/10.1016/j.enbuild.2004.01.050

Dingman, S. L. (2014). Physical Hydrology, 2nd Edition, Waveland Press, In

Gross, G. (2017). Some effects of water bodies on the environment-numerical experiments. Journal of Heat Island Institute International, 12, 2. https:// doi.org/10.1212/WNL.0000000000003470

Gunawardena, K. R., Wells, M. J., \& Kershaw, T. (2017). Utilising green and bluespace to mitigate urban heat island intensity. Science of the Total Environment, 584-585, 1040-1055. https://doi. org/10.1016/j.scitotenv.2017.01.15

Harman, I. N. \& Belcher, S.E. (2006). The surface energy balance and boundary layer over urban street canyon. Quarterly Journal of the Royal Meteorological Society, 132(621), 2749-2768. https://doi: 10.1256/ qj.05.185

Jacobs, C., Klok, L., Bruse, M., Cortesão, J., Lenzholzer, S., \& Kluck, J. (2020). Are urban water bodies really cooling? Urban Climate, 32, 100607. https://doi. org/10.1016/j.uclim.2020.100607

Jin, H., Shao, T., \& Zhang, R. (2017). Effect of water body forms on microclimate of residential district. Energy Procedia, 134, 256-265. https://doi. org/10.1016/j.egypro.2017.09.615

Kanda, M. (2006). Progress in the scale modelling of urban climate: Review. Theoretical and Applied Climatology, 84, 23-33. https://doi.org/10.1007/ s00704-005-0141-4

Kanda, M., Kanega, M., Kawai, T., Moriwaki, R. \& Sugawara, H. (2007). Roughness lengths for momentum and heat derived from outdoor urban scale models. Journal of Applied Meteorology and Climatology, 46, 1067-1079. https://doi.org/10.1175/ JAM2500.1

Kawai, T., \& Kanda, M. (2010a). Urban Energy Obtained from the Comprehensive Outdoor Scale Model Experiment. Part 1: Basic Features of the Surface Energy Balance. Journal of Applied Meteorology and Climatology, 49, 1341-1359. https://doi. org/10.1175/2010JAMC1992.1

Kawai, T., \& Kanda, M. (2010b). Urban Energy Obtained from the Comprehensive Outdoor Scale Model Experiment. Part 2: Comparisons with Field Data Using an Improved Energy Partition. Journal of Applied Meteorology and Climatology, 49, 13601376. https://doi.org/10.1175/2010JAMC1993.1

Landsberg, H. E. (1981). The Urban Climate. Academic Press, London

Li, C. \& Yu, C. W. (2014). Mitigation of urban heat development by cool island effect of green space and water body. Proceedings of the 8th International Symposium on Heating, Ventilation and Air Conditioning, 551-561.

Lin, Y., Wang, Z., Jim, C. Y., Li, J., Deng, J., Liu, J. (2020). Water as an urban heat sink: Blue infrastructure alleviates urban heat island effect in mega-city agglomeration. Journal of Cleaner Pro- 
duction, 262, 121411. https://doi.org/10.1016/j. jclepro.2020.121411

Oke T.R. (1987) Boundary Layer Climates, Routledge, London.

Paramita, B., \& Matzarakis, A. (2019). Urban morphology aspects on microclimate in a hot and humid climate. Geographica Pannonica, 23(4), 398410. https://doi.org/10.5937/gp23-24260

Paramita, B. \& Fukuda, H. (2014). Heat intensity of urban built environment in hot humid climate region. American Journal of Environmental Sciences, 10(3), 210-218. https://doi.org/10.3844/ ajessp.2014.210.218

Park, M., Hagishima, A., Tanimoto, J. \& Narita, K. I. (2012). Effect of urban vegetation on outdoor thermal environment: field measurement at a scale model site. Building and Environment, 56, 38-46. https://doi.org/10.1016/j.buildenv.2012.02.015

Pearlmutter, D., Kruger, E. L., \& Berliner, P. (2009). The role of evaporation in the energy balance of an open-air scaled urban surface. International Journal of Climatology, 29, 911 - 920. https://doi. org/10.1002/joc. 1752

Robitu, M., Musy, M., Inard, C., \& Groleau, D. (2006). Modeling the influence of vegetation and water pond on urban microclimate. Solar Energy, 80(4), 435-447, https://doi.org/10.1016/j.solener.2005.06.015

Steeneveld, G. J., Koopmans, S., Heusinkveld, B. G., Theeuwes. N. E. (2014) Refreshing the role of open water surfaces on mitigating the maximum urban heat island effect. Landscape and Urban Plan- ning, 121, 92-96, https://doi.org/10.1016/j.landurbplan.2013.09.001

Syafii, N. I., Ichinose, M., Kumakura, E., Jusuf, S. K., Chigusa, K., \& Wong, N. H. (2017). Thermal environment assessment around bodies of water in urban canyons: A scale model study. Sustainable Cities and Society, 34, 79-89. https://doi.org/10.1016/j. scs.2017.06.012

Theeuwes, N. E., Solcerová, A., \& Steeneveld, G. J. (2013). Modeling the influence of open water surfaces on the summertime temperature and thermal comfort in the city. J. Geophys. Res. Atmos., 118, 8881-8896. http://dx.doi.org/10.1002/jgrd.50704

Tzavali, A., Paravantis, J., Mihalakakou, G., Fotiadi, A., \& Stigka, E. (2015). Urban heat island intensity: A literature review. Fresenius Environmental Bulletin, 24, 4537-4554.

Van Hove, L.W.A., Jacobs, C.M.J., Heusinkveld, B.G., Elbers, J.A., van Driel, B.L., \& Holtslag, A.A.M. (2015). Temporal and spatial variability of urban heat island and thermal comfort within the Rotterdam agglomeration, [special issue: climate adaptation in cities]. Building and Environment, 83, 91103. https://doi.org/10.1016/j.buildenv.2014.08.029

Varquez, A.C.G., \& Kanda, M. (2018). Global urban climatology: a meta-analysis of air temperature trends (1960-2009). npj Clim Atmos Sci 1, 32. https://doi.org/10.1038/s41612-018-0042-8

Völker, S., Baumeister, H., Claßen, T., Hornberg, C., \& Kistemann, T. (2013). Evidence for the temperature-mitigating capacity of urban blue space - A health geographic perspective. Erdkunde, 67, 355371. https://doi.org/10.3112/erdkunde.2013.04.05. 